\title{
HPV prevalence around the time of sexual debut in adolescent girls in Tanzania
}

Baisley KJ, ${ }^{1}$ Andreasen A, ${ }^{2,3}$ Irani J, ${ }^{2,3}$ Nnko S, ${ }^{4}$ Changalucha J, ${ }^{4}$ Crucitti T, ${ }^{5}$ Francis SC, ${ }^{1}$ Holm Hansen C, ${ }^{1,2,6}$ Hayes RJ, ${ }^{1}$ Buvé A, ${ }^{7}$ Watson-Jones D ${ }^{2,3}$

${ }^{1}$ MRC Tropical Epidemiology Group, London School of Hygiene and Tropical Medicine, Keppel Street, London, WC1E 7HT, UK

${ }^{2}$ Mwanza Intervention Trials Unit, National Institute for Medical Research, Mwanza, Tanzania

${ }^{3}$ Department of Clinical Research, London School of Hygiene \& Tropical Medicine, Keppel Street, London, WC1E 7HT, UK

${ }^{4}$ National Institute for Medical Research, Mwanza, Tanzania

${ }^{5}$ HIV/STI Reference Laboratory, Department of Clinical Sciences, Institute of Tropical Medicine, Antwerp, Belgium

${ }^{6} \mathrm{MRC} / \mathrm{UVRI}$ and LSHTM, Uganda Research Unit, Entebbe, Uganda

${ }^{7}$ Unit of Epidemiology and Control of HIV/STD, Department of Public Health, Institute of Tropical Medicine, Antwerp, Belgium

Corresponding author: Kathy Baisley. Telephone $+44(0) 207927$ 2019. Email: kathy.baisley@lshtm.ac.uk

Running head: HPV among young Tanzanian girls

Word count: 3267 (revised after review) 


\section{Key Messages:}

- HPV infection among adolescent girls attending secondary school in Tanzania was high (32.5\%), and high-risk (HR) oncogenic genotypes were detected in over half the girls with HPV infection

- HPV infection was inversely associated with Lactobacillus species, key constituents of optimal vaginal microbiota.

- The Tanzanian national programme is vaccinating with Gardasil, which protects against 2/13 (15\%) HR genotypes circulating in our study population, including the most prevalent one (HPV-16).

- Extending the age range of vaccination in this region, where cervical cancer screening is extremely limited, may be cost-effective. 


\section{Abstract}

Objectives: Cervical cancer is the leading cause of cancer-related mortality among women in sub-Saharan Africa (SSA). Data on HPV epidemiology in adolescent girls in SSA are essential to inform HPV vaccine policy recommendations for cervical cancer prevention. We assessed the burden of HPV infection, and risk factors for infection, among adolescent girls around the time of sexual debut.

Methods: Cross-sectional study of secondary school girls aged 17-18 years in Tanzania. Consenting participants provided samples for HPV and STI testing. Vaginal swabs were tested for 37 HPV genotypes by Roche Linear Array®. Logistic regression was used to identify factors associated with HPV infection. Y-chromosome was tested as a marker of recent condom-less sex.

Results: $163 / 385$ girls (42.3\%) reported previous penetrative sex. HPV was detected in 125/385 (32.5\%) girls, including 84/163 (51.5\%) girls reporting previous sex and 41/222 (18.5\%) reporting no previous sex. High-risk (HR) genotypes were detected in 70/125 (56.0\%) girls with HPV infection. The most common HR genotype was HPV-16 $(15 / 385 ; 3.9 \%)$. The prevalence of other HR HPV vaccine genotypes was between $0.8 \%-$ 3.1\%. Among 186 girls who reported no previous sex, were negative for Y-chromosome and had no sexually transmitted infections, 32 (17\%) had detectable HPV. Lactobacillus species and bacterial vaginosis (BV)-associated bacteria were negatively and positively associated, respectively, with HPV.

Conclusions: HPV prevalence among adolescent girls around the time of sexual debut was high. However, prevalence of most vaccine genotypes was low, indicating that extending the age range of HPV vaccination in this region may be cost-effective. 


\section{INTRODUCTION}

Cervical cancer is the leading cause of cancer mortality among women in sub-Saharan Africa (SSA), and East Africa bears one of the highest burdens, with an age-standardised incidence of 40/100,000 and mortality rate of 30/100,000.[1] Almost all cervical cancers can be attributed to persistent infection with one of 13 high-risk (HR) genotypes of human papillomavirus (HPV).[2] In addition to its oncogenic potential, HPV may also be an important co-factor in HIV acquisition.[3]

Infection with up to $7 \mathrm{HR}$ and 2 low risk (LR) HPV genotypes can be prevented with HPV vaccination.[4] However the vaccine offers less protection once an HPV genotype has been acquired. Vaccination is recommended before first sex since the predominant mechanism of HPV acquisition is thought to be through penetrative sex.[5] HPV incidence increases rapidly after first sex and with changes of sexual partner, although most infections are cleared within 12 months.[6,7] Reviews of global age-specific HPV prevalence show the highest prevalence in women aged $<25$ years.[8] Most women are assumed to be HPV negative before first sex; however, some studies have detected HPV in girls and young women who report no previous penetrative sex.[9,10]

The few published studies on HPV infection in adolescent girls in SSA suggest that HPV prevalence may be very high at a young age. A study in Tanzania found HPV prevalences of $73 \%$ in sexually active girls aged $14-18$ years, and one in Uganda in girls aged 12-24 found a prevalence of 75\%.[11,12] A recent study in Tanzanian girls aged 15-16 years who reported no previous penetrative sex found an HPV prevalence of 8\%.[13] The prevalence of non-optimal vaginal microbiota, including bacterial vaginosis (BV), is particularly high in SSA.[14] The vaginal microbiome may modulate susceptibility to HPV infection, as well as other sexually transmitted infections (STI) and HIV.[15] 
There is an important need for data on HPV epidemiology in adolescent girls in SSA in order to inform HPV vaccine policy recommendations, to help allocate scarce publichealth resources efficiently and achieve the greatest public health gains, especially as vaccine supplies are currently constrained.[16] Policymakers in SSA may not be able to draw conclusions from other settings because of differences in demographic structure, sexual behaviour, HPV genotype distribution, and co-factors such as HIV infection. As part of a cross-sectional study of the vaginal microbiota of girls aged 17-18 years in secondary schools in Tanzania, over half of whom reported no previous sex, we measured the burden of HPV infection and risk factors for infection.

\section{METHODS}

\section{Study design}

The study design and procedures have been reported previously.[17] Briefly, this was a cross sectional survey in Mwanza, north-western Tanzania. Girls were enrolled between November 2013-June 2014 from government-funded secondary schools; selected schools had at least 25 girls in the target age range. Inclusion criteria were being aged 17-18 years, resident in Mwanza, and planning to stay in Mwanza for 1 month post-enrolment. Exclusion criteria were being outside the age range; being unwilling/unable to provide informed assent/consent (or parent unable/unwilling to provide informed consent, if aged 17); being temporarily in Mwanza, or planned travel within 1 month postenrolment.

Girls were interviewed about socio-demographics, hygiene practices, and sexual behaviours. Participants provided 5 self-administered vaginal swabs in the presence of a nurse who assisted them if needed. Blood and urine samples were collected. Participants 
were offered HIV voluntary counselling and testing, with referral for care if positive. Laboratory results for treatable STI and free treatment as required were provided to participants within 2 weeks.

\section{Laboratory methods}

Laboratory procedures have been described previously.[17] HPV genotyping used the Linear Array HPV Genotyping assay (Roche Molecular Systems, USA), which detects 37 genotypes. DNA was extracted using the AmpliLute Liquid Media Extraction kit (Roche Molecular Systems), and amplified using the Linear Array HPV Genotyping Test. Generated amplicons were detected using the Linear Array Detection Kit. PCR reaction in this assay is based on a multiplex system, including human $\beta$-globin amplification primers, as an internal control for specimen quality. Specimens consistently negative for $\beta$-globin amplification were excluded since it was assumed that vaginal sampling was unsuccessful, or the extraction or amplification failed. DNA extraction, amplification and typing were performed in different rooms and included negative processing controls.

Vaginal swabs were tested for Neisseria gonorrhoeae (NG), Chlamydia trachomatis (CT) and Mycoplasma genitalium (MG) by in-house real-time PCR.[17] Concentrations of Lactobacillus crispatus, L. gasseri, L. jensenii, L. iners, L. vaginalis, Gardnerella vaginalis, Atopobium vaginae were measured using quantitative (q)PCR as previously described,[18] with DNA extraction by the QIAmp DNA mini kit. Primers and probes were from Eurogentec S.A. (Belgium) and PCRs were run on the QIAGEN Rotorgene. Gramstained vaginal smears were examined for BV using the Nugent score. Trichomonas vaginalis (TV) was diagnosed by culture (InPouch TV, BioMed Diagnostics, USA). Serum samples were tested for HSV-2 antibodies by ELISA (Kalon Biological, UK). Syphilis was determined by Immutrep Rapid Plasma Reagin (Omega Diagnostics, Scotland) and 
Treponema pallidum particle agglutination assay (SERODIA, Fujirebio, Japan). Blood samples were tested with Determine HIV1/2 rapid test (Alere, Japan), then Uni-Gold HIV (Trinity Biotech, Ireland) if reactive. If both tests were reactive, the result was deemed positive. If tests were discordant, the sample was tested with HIV1/2 Stat-Pak (Chembio, USA), and deemed positive if reactive. Swabs from girls who reported no previous sex were tested for Y-chromosome using an in-house real time PCR, as a marker of recent condom-less sex.[19] Y-chromosome can be detected for up to 15 days, so may provide a rough measure of reporting bias.

Except for Y-chromosome testing, all tests were done at the National Institute for Medical Research (NIMR) laboratory, Mwanza. Quality assurance (QA) and Y-chromosome testing were performed by the STI Reference Laboratory at ITM Antwerp.

\section{Statistical methods}

Questionnaire data were double-entered into OpenClinica (Akaza Research, USA), and analysed using STATA V14.0 (StataCorp, USA).

Participant characteristics, and the number of infections of each HPV genotype, were tabulated among girls who reported no previous penetrative sex and those who had passed sexual debut (termed 'sexually active'). Socioeconomic status was measured using a deprivation score, based on household ownership of 3 items: 1=car (least deprived); $2=$ television, without car; $3=$ mobile phone, without car or television; $4=$ none of the 3 items (most deprived). We used logistic regression to estimate odds ratios (OR) and 95\% confidence intervals (CI) for factors associated with any HPV infection among all girls. Potential determinants of HPV infection were examined using a conceptual framework with 3 levels: sociodemographic, behavioural, and biological factors. Age was considered 
an a priori confounder and included in all models. First, sociodemographic factors whose age-adjusted association with HPV infection was significant at $\mathrm{p}<0.10$ were included in a multivariable model; those remaining associated at $\mathrm{p}<0.10$ were retained. Behavioural factors were then added to this model one by one. Those that were associated with HPV at $\mathrm{p}<0.10$, after adjusting for sociodemographic factors, were retained if they remained significant at $\mathrm{p}<0.10$. Associations with biological factors were determined in a similar way. This strategy allowed us to assess the effects of variables at each level of the framework, adjusted for more distal variables. We used a similar approach to examine sexual behaviour factors associated with HPV infection among girls who reported being sexually active.

\section{Ethical considerations}

The Institutional Review Board of the Institute of Tropical Medicine in Antwerp (867/13), the Ethics Committee of the University Teaching Hospital in Antwerp (13/14/147), the Lake Zone Institutional Review Board in Mwanza (MR/53/100/86) and the National Ethics Committee of the NIMR Coordinating Committee (NIMR/HQ/R.8a/Vol.IX/1544) approved the study protocol. All participants provided written informed consent/assent; written parental consent was required for participants $<18$ years.

\section{RESULTS}

\section{Characteristics of study participants}

We identified 26 eligible secondary schools; 24 participated in the study. 1210 girls aged 17-18 years were registered on the school lists; 802 (66\%) were located and their parents invited to a meeting about the study. 439 parents (55\%) attended the meeting and 421 (96\%) agreed to their daughter's participation. 401/421 (95\%) girls consented/assented 
and were enrolled (50\% of those located; $33 \%$ of those on the school lists). Of these, 385 (97\%) had HPV results and were included in the analysis.

Overall, 222 (58\%) participants reported never having had penetrative sex. Of those who reported previous sex, 61\% (99) had passed sexual debut in the past year. Sexually active girls were older than those who reported no previous sex (51\% vs. 39\% aged 18 years, respectively; $\mathrm{p}=0.02$ ); however, there was no evidence of a difference in other sociodemographic characteristics (Table 1). Nearly all participants $(381 ; 99 \%)$ had passed menarche, at a median age of 14 years (IQR 14-15). Among girls who reported no previous sex, 20 (9\%) reported non-penetrative sexual contact with a male partner (e.g. kissing, genital touching).

The overall prevalence of any STI was $21 \%$ among girls who reported previous sex (TV 9\%, CT 5\%, NG 2\%, MG 4\%, HSV2 3\%, HIV 0\%), and 7\% among girls who reported no previous sex (TV 1\%, CT <1\%, NG 1\%, MG 1\%, HSV2 2\%, HIV 1\%). BV prevalence among girls who reported previous sex was 33\%, and 19\% among those reporting no previous sex.

\section{Prevalence of HPV genotypes}

$387 / 401$ girls provided vaginal swabs for HPV testing ( 6 were pregnant, 8 refused); $\beta$ globin was detected in 385/387 specimens. The prevalence of any HPV infection was $32.5 \%$ (125/385); 64/125 girls (51.2\%) with HPV infection had >1 genotype. The most prevalent HR genotypes were HPV-16 (3.9\%), HPV-39 and HPV-52 (both 3.1\%), and HPV58 (2.9\%) (Figure 1). HPV-18 was detected in 3 girls (0.8\%). 17 girls (4.4\%) were infected with HPV-16 and/or HPV-18, the HR genotypes targeted by all HPV vaccines. 53 girls 
(13.8\%) were infected with a genotype targeted by the new 9-valent HPV vaccine, Gardasil-9.

HPV prevalence varied by self-reported sexual behaviour (online supplementary material Table S1; Figures S1 and S2). HPV was detected in 84/163 (51.5\%) sexually active girls and 41/222 (18.5\%) girls who reported no penetrative sex. HR HPV was detected in 47 (28.8\%) sexually active girls, and $23(10.4 \%)$ who reported no penetrative sex. Among those with HR HPV, $31.9 \%$ of sexually active girls and $13.0 \%$ of those who reported no penetrative sex were infected with $>1$ HR genotype. The most common HR genotypes among sexually active girls were HPV-52 (6.7\%), HPV-16 (5.5\%), HPV-39 and HPV-68 (both 4.9\%). Among girls who reported no penetrative sex, the most common HR genotypes were HPV-16 and HPV-58 (both 2.7\%).

Among the 222 girls who reported no penetrative sex, 19 (9\%) were either positive for Ychromosome $(\mathrm{N}=7)$ or had laboratory-confirmed STI other than HPV $(\mathrm{N}=12)$. HPV prevalence among the 186 girls who reported no sexual contact nor penetrative sex, and had no evidence of Y chromosome nor any STI, was 17.2\% (N=32).

\section{Factors associated with HPV infection}

In the unadjusted analysis among all girls, there was some evidence of an association of HPV with increasing deprivation score, and strong evidence of an association with sexual behaviour (penetrative sex, kissing, engaging in genital touching; Table 2). There was also evidence of an association with vaginal cleansing and menstrual hygiene. After adjusting for age, deprivation score and penetrative sex, there was still strong evidence of an association with menstrual hygiene $(\mathrm{p}=0.004)$, with participants who used cloths instead of commercial pads having the lowest odds of HPV infection, and those who used only 
underwear having the highest odds of infection. There was also weak evidence of an association with vaginal cleansing $(\mathrm{aOR}=1.70,95 \% \mathrm{CI}=0.92-3.16, \mathrm{p}=0.09)$. After adjusting for age, deprivation score, penetrative sex, menstrual hygiene and vaginal cleansing, there was evidence of an association with gonorrhoea (aOR=5.70, 95\% $\mathrm{CI}=0.91-35.6)$, MG $(\mathrm{aOR}=6.01,95 \% \mathrm{CI}=1.08-33.6), \mathrm{HIV}(\mathrm{aOR}=10.4,95 \% \mathrm{CI}=0.90-121.5)$ and $\mathrm{BV}(\mathrm{aOR}=1.93$, $95 \% \mathrm{CI}=1.13-3.29)$.

Among sexually active girls, after adjusting for age and deprivation score, there was evidence of an association of HPV with having $>1$ lifetime partner (aOR=2.63, 95\% $\mathrm{CI}=1.22-5.69)$, an older first partner, and a first partner who had concurrent partners (online supplementary material Table S2). There was also evidence of an association with time since sexual debut, with HPV infection highest among those whose sexual debut was 1-2 years ago $(\mathrm{aOR}=2.29,95 \% \mathrm{CI}=1.01-5.21$, relative to those with sexual debut $<1$ year ago).

\section{Association with vaginal microbiota}

Among all girls, after adjusting for age, deprivation score and penetrative sex, HPV infection was positively associated with $A$. vaginae $(\mathrm{aOR}=2.19,95 \% \mathrm{CI}=1.32-3.64$; $\mathrm{p}=0.002)$ and $\mathrm{G}$. vaginalis $(\mathrm{aOR}=1.79,95 \% \mathrm{CI}=1.05-3.04)$ (Table 3). In contrast, HPV infection had an inverse association with several Lactobacillus species, including $L$. crispatus $(\mathrm{aOR}=0.48,95 \% \mathrm{CI}=0.29-0.80 ; \mathrm{p}=0.005)$ and L. jensenii $(\mathrm{aOR}=0.44,95 \% \mathrm{CI}=0.27-$ 0.73; $\mathrm{p}=0.001$ ), and, to a lesser extent, $L$ vaginalis. The same trends were seen for the association with high levels ( $>1$ million cells $/ \mathrm{mL}$ ) of each bacterial species. 


\section{DISCUSSION}

We found a high prevalence of HPV infection among adolescent Tanzanian girls around the time of reported sexual debut. Over half of sexually active participants and one-fifth of those who reported no penetrative sex had HPV infection, and $56 \%$ of those infected had an HR genotype. Multiple HPV genotype infections were also very common, with 51\% of HPV-infected girls having $>1$ genotype. These findings are consistent with previous studies of HPV in sexually active adolescents in the USA and in Africa.[11,12,20]

HPV-16 was the most prevalent HR genotype (3.9\%). The prevalence of HPV-18 was $<1 \%$ and of other vaccine genotypes was $<3 \%$, except for HPV-52 (targeted by Gardasil-9), which was 3.1\%. Similarly, a study in Mozambique found HPV-52, 58 and 16 were the most common HR genotypes in young women.[21] Also, a large meta-analysis of HPV prevalence worldwide found HPV-16 to be the most common genotype among women in SSA, followed by HPV-52.[8]

The Director General of the World Health Organization recently announced a goal to eliminate cervical cancer.[22] Currently vaccination strategies target girls in an age range considered to be pre-sexual debut, typically 9-14 years. The optimum upper age limit for vaccination will depend on different factors including HPV vaccine genotype prevalence, age of sexual debut, cost per dose of vaccine, availability of cervical cancer screening, and HPV transmission dynamics. Screening for cervical cancer is extremely limited in Tanzania. Previous studies of HPV epidemiology in Tanzania have shown one of the highest reported HPV incidences, and a high prevalence of vaccine-related genotypes among young women aged 20-25 years, so the cost-effectiveness of vaccinating girls up to 17 years is likely to be high.[11] Over half the girls in our study reported no previous penetrative sex, and most were not yet infected with vaccine-related genotypes. These 
findings suggest that a catch-up strategy that goes beyond the multiyear cohort approach of vaccinating 9-14 year olds,[23] by offering vaccination to girls aged 15-17 years, could help reduce HPV acquisition at a critical time after sexual debut. Furthermore, this would contribute towards the goal of cervical cancer elimination by decreasing the proportion of females in the population who would otherwise acquire persistent HPV infection, a necessary prerequisite for cervical cancer.

The Tanzanian national programme is currently vaccinating with Gardasil, which covers 2/13 (15\%) circulating HR genotypes in our study population, but only one of the more common ones (HPV-16). In contrast, Gardasil-9 would cover 7/13 (54\%) circulating HR genotypes, including the three most common ones. Although Gardasil and Cervarix offer some cross-protection for other genotypes (Gardasil against HPV-31, and Cervarix against HPV-31, 33, and 45), these cross-protected genotypes were less common in our population. Therefore, Gardasil-9 may offer the best coverage given the distribution of HR genotypes in our setting.

HPV transmission appears extremely efficient in the early years of sexual activity in our setting, with $>60 \%$ of girls whose sexual debut was $1-2$ years ago being infected with HPV. HPV prevalence among girls who report no penetrative sex was also high (18.5\%), and substantially higher than in studies in industrialised countries among women who reported no previous sex. A cross-sectional study in Sweden in women aged 10-25 years who reported no previous sex found a prevalence of 1.5\%.[10] A longitudinal study in USA found HPV in only $1.7 \%$ of samples from women aged 18-20 who never had sex.[9] Our prevalence is also higher than in a longitudinal study in Tanzanian girls aged 15-16 years who reported no penetrative sex over 18 months, which found HPV in only $11.6 \%$ of samples.[24] Lack of disclosure is likely to be part of the explanation for the high HPV 
prevalence in girls in our study who denied previous sexual activity. This is supported by our finding that $9 \%$ of girls who reported no previous sex were positive for Ychromosome and/or an STI (excluding HPV). In Tanzania, girls who are still in school may be particularly reluctant to disclose sexual activity, since potential consequences include expulsion, physical punishment or social exclusion.[25]

Alternative explanations for HPV infection in girls who report no previous sex include mother-to-child transmission, non-penetrative sexual contact, or transmission via fomites.[26,27] A recent study in Mwanza showed a high prevalence of HPV DNA in oral washes and fingertip samples from adolescent girls, and on surfaces in their bathrooms.[28] Nevertheless, even with potential reporting errors, our findings of a very high HPV prevalence in girls who report no penetrative sex is important.

After adjusting for potential confounders, we found a strong inverse association between HPV and D-lactic-acid and $\mathrm{H}_{2} \mathrm{O}_{2}$-producing Lactobacillus species, including L. crispatus and L. jensenii, key constituents of optimal vaginal microbiota. Furthermore, there was a strong positive association between HPV infection and anaerobic bacterial species $G$. vaginalis and $A$. vaginae. These species are characteristic of $\mathrm{BV}$, which has been associated with increased susceptibility to STI and HIV.[29] A recent meta-analysis found that disturbance in the vaginal microbiota away from a Lactobacillus-dominated environment was associated with increased risk of HPV acquisition and persistence, and related cervical disease.[30]

Strengths of our study include detailed interviews given by trained nurses experienced in adolescent sexual behaviour research. Collection of vaginal swabs, although selfadministered, was observed by nurses; all but 2 specimens contained $\beta$-globin, indicating successful sampling and specimen processing. The Roche Linear Array used for HPV 
genotyping has a high sensitivity and specificity; all laboratory assays were conducted according to SOPs with external QA at an internationally-recognised reference laboratory. Limitations include the cross-sectional design, which makes it difficult to assess causality or to measure past HPV infection, since individual genotype-specific infections may be rapidly cleared.[7] Face-to-face interviews may have increased social desirability bias in responses; the inclusion of parents and recruitment from schools may have compounded this issue. We enrolled girls who were still in school; many girls in this age range in Tanzania are no longer in school. Unpublished demographic and health survey (DHS) data from the Mwanza region in 2017 showed 41\% of girls aged 17-18 years were still in school. Furthermore, only $33 \%$ of 1210 girls on the school lists were enrolled, mostly because they were not found at the school or their parents could not be located, which suggests possible selection bias. National DHS data show that young women with secondary education have an older age at first sex, and later age at first birth.[31] Therefore, we may have underestimated HPV prevalence among all women in this age group. However, our findings of the distribution of HPV genotypes, and factors associated with HPV, are consistent with other studies in SSA, and may be more broadly generalisable.

In conclusion, we found a high prevalence of HPV infection, and HR genotypes, among adolescent girls in the early years after becoming sexually active, and among girls who reported no penetrative sex. HPV vaccination in Tanzania is currently offered to 14 year old girls through a national vaccination programme. The prevalence of most vaccinerelated genotypes was low, indicating that extending the age range of HPV vaccination through a catch-up campaign in this region, with one of the highest rates of cervical cancer worldwide and limited facilities for screening, may be cost-effective. 


\section{ACKNOWLEDGMENTS}

We would like to express our gratitude to the parents and participants for who gave up their time and provided samples for this study, and to our dedicated study nurses and clinical officers: Fidelis Malifedha, Beatrice Kamala, Justa Lucas, Esther Mwinuka, Herijema Yona, and AnnaMaria King, and our field tracing team: Deborah Byabato, Scholastica Magucha, Cecilia Paul, Malilo Juma, Dickson Rubirya, Enos Mbata, Mathias Godda and Damian Dotto. We also thank the laboratory team, and Simon Buhalata for technical assistance in Nugent scoring, and Rama Hashim for data management. Finally, we thank administrative and support staff at the Mwanza Interventional Trials Unit and the Institute of Tropical Medicine for their contribution to this study.

\section{COMPETING INTERESTS}

DWJ has received research grants from GSK Biologicals for HPV vaccine-related research. All other authors declare that they have no conflicts of interest.

\section{FINANCIAL SUPPORT}

This work was supported by the European and Developing Countries Clinical Trials Partnership (project code: SP.2011.41304.066). Additionally, KJB, SCF and RJH received salary support through a jointly funded award by the UK Medical Research Council (MRC) and the UK Department for International Development (DFID) under the MRC/DFID Concordat agreement which is also part of the EDCTP2 programme supported by the European Union (MR/R010161/1). The funders had no role in study design, data collection and analysis, decision to publish, or preparation of the manuscript. 


\section{REFERENCES}

[1] Bray F, Ferlay J, Soerjomataram I, Siegel RL, Torre LA, Jemal A. Global cancer statistics 2018: GLOBOCAN estimates of incidence and mortality worldwide for 36 cancers in 185 countries. CA Cancer J Clin 2018; 68(6):394-424

[2] Bouvard V, Baan R, Straif K, et al. A review of human carcinogens--Part B: biological agents. The Lancet Oncology 2009; 10(4):321-2.

[3] Houlihan CF, Larke NL, Watson-Jones D, et al. Human papillomavirus infection and increased risk of HIV acquisition. A systematic review and meta-analysis. AIDS 2012; 26(17):2211-22

[4] Harper DM, DeMars LR. HPV vaccines - A review of the first decade. Gynecol Oncol 2017; 146(1):196-204.

[5] Szarewski A, Poppe WA, Skinner SR, et al. Efficacy of the human papillomavirus (HPV)-16/18 AS04-adjuvanted vaccine in women aged 15-25 years with and without serological evidence of previous exposure to HPV-16/18. Int J Cancer 2012;131(1):10616

[6] Moscicki AB, Schiffman M, Burchell A, et al. Updating the natural history of HPV and anogenital cancer. Vaccine 2012; 30 Suppl 5:F24-33.

[7] Giuliano A, Harris R, Sedjo RL, et al. Incidence, prevalence, and clearance of typespecific human papillomavirus infections: The Young Women's Health Study. J Infect Dis $2002 ; 186(4): 462-469$.

[8] Bruni L, Diaz M, Castellsagué X, Ferrer E, Bosch FX, Sanjosé S de. Cervical human papillomavirus prevalence in 5 continents: meta-analysis of 1 million women with normal cytological findings. J Infect Dis 2010; 202(12):1789-99. 
[9] Winer R, Lee S, Hughes J, Adam DE, Kiviat NB, Koutsky LA. Genital human papillomavirus infection: incidence and risk factors in a cohort of female university students. Am J Epidemiol 2003; 157(3):218-226.

[10] Rylander E, Ruusuvaara L, Almströmer MW, Evander M, Wadell G. The absence of vaginal human papillomavirus 16 DNA in women who have not experienced sexual intercourse. Obstet Gynecol 1994;83(5 Pt 1):735-7.

[11] Watson-Jones D, Baisley K, Brown J, et al. High prevalence and incidence of human papillomavirus in a cohort of healthy young African female subjects. Sex Transm Infect $2013 ; 89(5): 358-65$.

[12] Banura C, Sandin S, van Doorn LJ, et al. Type-specific incidence, clearance and predictors of cervical human papillomavirus infections (HPV) among young women: a prospective study in Uganda. Infect Agent Cancer 2010; 5:7.

[13] Houlihan CF, de Sanjosé S, Baisley K, et al. Prevalence of human papillomavirus in adolescent girls before reported sexual debut. J Infect Dis 2014; 210(6):837-45. [14] Kenyon C, Colebunders R, Crucitti T. The global epidemiology of bacterial vaginosis: a systematic review. Am J Obstet Gynecol 2013;209:505-23.

[15] Tamarelle J, Thiébaut ACM, de Barbeyrac B, Bébéar C, Ravel J, DelarocqueAstagneau E. The vaginal microbiota and its association with human papillomavirus, Chlamydia trachomatis, Neisseria gonorrhoeae and Mycoplasma genitalium infections: a systematic review and meta-analysis. Clin Microbiol Infect. 2019 Jan;25(1):35-47 [16] Dull P. HPV vaccination scale-up in low and middle-income countries: vaccine supply and pipeline challenges. Presentation at the 32nd International Papillomavirus Conference; 2018 2-6 October; Sydney. 
[17] Francis SC, Holm Hansen C, Irani J, et al. Results from a cross-sectional sexual and reproductive health study among school girls in Tanzania: high prevalence of bacterial vaginosis. Sex Transm Infect 2018; Dec 5.

[18] Jespers V, Menten J, Smet H, et al. Quantification of bacterial species of the vaginal microbiome in different groups of women, using nucleic acid amplification tests. BMC Microbiol 2012; May 30;12:83.

[19] Jacot TA, Zalenskaya I, Mauck C, Archer DF, Doncel GF. TSPY4 is a novel spermspecific biomarker of semen exposure in human cervicovaginal fluids; potential use in HIV prevention and contraception studies. Contraception. 2013;88(3):387-95.

[20] Brown D, Shew M, Qadadri B, et al. A longitudinal study of genital human papillomavirus infection in a cohort of closely followed adolescent women. J Infect Dis 2005; 191(2):182-192.

[21] Omar VE, Orvalho A, Nália I, et al. Human papillomavirus prevalence and genotype distribution among young women and men in Maputo city, Mozambique. BMJ Open. 2017; 7(7): e015653

[22] World Health Organization. Director General Call to Action. May 2018. Available at: https://www.who.int/reproductivehealth/DG Call-to-Action.pdf. Accessed 12 November 2018

[23] GAVI. Application Guidelines: GAVI's Support to Countries. February 2018. Available at: https://www.gavi.org/support/process/apply/vaccine/\#hpv. Accessed 12 November 2018.

[24] Houlihan CF, Baisley K, Bravo IG, et al. The Incidence of human papillomavirus in Tanzanian adolescent girls who report no previous sex. J Adolesc Health 2016; 58(3):295-301. 
[25] Plummer M, Wight D. Young People's Lives and Sexual Relationships in Rural Africa: Findings from a Large Qualitative Study in Tanzania. Lexington Books; 2011. [26] Bosch FX, de Sanjose S. The epidemiology of human papillomavirus infection and its association with cervical cancer. Dis Markers 2007; 23(4):213-227.

[27] Burchell AN, Winer RL, Sanjosé S de, Franco EL. Chapter 6: Epidemiology and transmission dynamics of genital HPV infection. Vaccine 2006; 24 Suppl 3:S3/52-61. [28] Houlihan CF, Baisley K, Bravo IG, et al. Human papillomavirus DNA detected in fingertip, oral and bathroom samples from unvaccinated adolescent girls in Tanzanian. Sex Transm Infect 2018; in press.

[29] van de Wijgert JH, Borgdorff $H$, Verhelst $R$, et al. The vaginal microbiota: what have we learned after a decade of molecular characterization? PLoS One 2014;9(8):e105998. [30] Brusselaers N, Shrestha S, Van De Wijgert J, Verstraelen H. Vaginal dysbiosis, and the risk of human papillomavirus and cervical cancer: systematic review and metaanalysis. Am J Obstet Gynecol 2018; Dec 11. [Epub ahead of print] [31] Tanzania Demographic and Health Survey and Malaria Indicator Survey 2015-2016. Dar es Salaam, Tanzania: MoHCDGEC, MoH, NBS, OCGS, and ICF. Available at http://dhsprogram.com/pubs/pdf/FR321/FR321.pdf. Accessed 20 April 2019. 
Table 1. Characteristics at enrolment of 385 adolescent girls attending secondary school in Mwanza, Tanzania

\begin{tabular}{|c|c|c|c|}
\hline & $\begin{array}{c}\begin{array}{c}\text { Report no } \\
\text { previous }\end{array} \\
\text { penetrative sex } \\
(\mathrm{N}=222) \\
\mathrm{n}(\text { column } \%)\end{array}$ & $\begin{array}{c}\text { Report previous } \\
\text { penetrative sex } \\
(\mathrm{N}=163) \\
n(\text { column } \%)\end{array}$ & $\begin{array}{l}\text { All girls }(\mathrm{N}=385) \\
\text { n (column\%) }\end{array}$ \\
\hline \multicolumn{4}{|l|}{ Sociodemographic } \\
\hline \multicolumn{4}{|l|}{ Age } \\
\hline 17 years & 135 (61\%) & $80(49 \%)$ & $215(56 \%)$ \\
\hline 18 years & 87 (39\%) & $83(51 \%)$ & $170(44 \%)$ \\
\hline \multicolumn{4}{|l|}{ Tribe } \\
\hline Sukuma & $99(45 \%)$ & $70(43 \%)$ & $169(44 \%)$ \\
\hline Non-Sukuma & $123(55 \%)$ & $93(57 \%)$ & $216(56 \%)$ \\
\hline \multicolumn{4}{|l|}{ Religion } \\
\hline Catholic & $97(44 \%)$ & 87 (53\%) & $184(48 \%)$ \\
\hline Other Christian & $88(40 \%)$ & $54(33 \%)$ & $142(37 \%)$ \\
\hline Muslim & $32(14 \%)$ & $20(12 \%)$ & $52(14 \%)$ \\
\hline Other & $5(2 \%)$ & $2(1 \%)$ & $7(2 \%)$ \\
\hline \multicolumn{4}{|l|}{ Secondary school form } \\
\hline Form 1 & $2(1 \%)$ & $1(1 \%)$ & $3(1 \%)$ \\
\hline Form 2 & $47(21 \%)$ & $21(13 \%)$ & $68(18 \%)$ \\
\hline Form 3 & $127(57 \%)$ & $99(61 \%)$ & $226(59 \%)$ \\
\hline Form 4 & $46(21 \%)$ & $42(26 \%)$ & $88(23 \%)$ \\
\hline \multicolumn{4}{|l|}{ Who lives with } \\
\hline Mother in household & $146(66 \%)$ & $98(60 \%)$ & $244(63 \%)$ \\
\hline Father but not mother & $12(5 \%)$ & $12(7 \%)$ & $24(6 \%)$ \\
\hline Neither mother or father & $64(29 \%)$ & $53(33 \%)$ & $117(30 \%)$ \\
\hline \multicolumn{4}{|l|}{ Deprivation score } \\
\hline 1 (least deprived) & $16(7 \%)$ & $8(5 \%)$ & $24(6 \%)$ \\
\hline 2 & $88(40 \%)$ & $76(47 \%)$ & $164(43 \%)$ \\
\hline 3 & $110(50 \%)$ & $73(45 \%)$ & $183(48 \%)$ \\
\hline 4 (most deprived) & $8(4 \%)$ & $6(4 \%)$ & $14(4 \%)$ \\
\hline \multicolumn{4}{|l|}{ Behavioural } \\
\hline \multicolumn{4}{|l|}{ Ever drink alcohol? } \\
\hline Yes & $6(3 \%)$ & $5(3 \%)$ & $11(3 \%)$ \\
\hline \multicolumn{4}{|l|}{ Ever kissed with tongues } \\
\hline Yes & $19(9 \%)$ & $76(47 \%)$ & 95 (25\%) \\
\hline \multicolumn{4}{|l|}{$\begin{array}{l}\text { Ever engaged in genital } \\
\text { touching } 1\end{array}$} \\
\hline Yes & $3(1 \%)$ & $40(25 \%)$ & $43(11 \%)$ \\
\hline \multicolumn{4}{|l|}{ Ever had oral sex² } \\
\hline Yes & $1(<1 \%)$ & $9(6 \%)$ & $10(3 \%)$ \\
\hline \multicolumn{4}{|l|}{ Ever had anal sex } \\
\hline Yes & 0 & $2(1 \%)$ & $2(1 \%)$ \\
\hline \multicolumn{4}{|l|}{ Passed menarche } \\
\hline Yes & $218(98 \%)$ & $163(100 \%)$ & $381(99 \%)$ \\
\hline
\end{tabular}


Ever cleanse inside vagina

Yes

${ }^{1}$ Sexual touching with a man/boy where girl touched his penis with her hand, he touched her vagina with his hand, or he rubbed his penis on her legs/buttocks/genitals but did not have vaginal sex. ${ }^{2}$ Ever had man/boy put his penis in girl's mouth, or he licked/sucked the girl's genitals. 
Table 2. Factors associated with any HPV infection among 385 adolescent girls attending secondary school in Mwanza, Tanzania

\begin{tabular}{|c|c|c|c|}
\hline & $\begin{array}{c}\text { N with HPV / total } \\
\text { N (\%) }\end{array}$ & $\begin{array}{l}\text { Crude OR } \\
(95 \% \mathrm{CI})\end{array}$ & \\
\hline \multicolumn{4}{|l|}{ Sociodemographic } \\
\hline Age & & $\mathrm{P}=0.40$ & \\
\hline 17 years & 66 / $215(30.7 \%)$ & 1 & \\
\hline 18 years & 59 / $170(34.7 \%)$ & $1.20(0.78-1.84)$ & \\
\hline Tribe & & $\mathrm{P}=0.85$ & \\
\hline Sukuma & 54 / $169(32.0 \%)$ & 1 & \\
\hline Non-Sukuma & 71 / 216 (32.9\%) & $1.04(0.68-1.60)$ & \\
\hline Religion & & $\mathrm{P}=0.60$ & \\
\hline Catholic & 59 / $184(32.1 \%)$ & 1 & \\
\hline Other Christian & $51 / 142(35.9 \%)$ & $1.19(0.75-1.88)$ & \\
\hline Muslim & 15 / $52(28.8 \%)$ & $0.86(0.44-1.69)$ & \\
\hline Other & $0 / 7(0.0 \%)$ & - & \\
\hline Who lives with & & $\mathrm{P}=0.86$ & \\
\hline Mother in household & 79 / $244(32.4 \%)$ & 1 & \\
\hline Father but not mother & $9 / 24(37.5 \%)$ & $1.25(0.53-2.99)$ & \\
\hline $\begin{array}{l}\text { Neither mother or } \\
\text { father }\end{array}$ & 37 / 117 (31.6\%) & $0.97(0.60-1.55)$ & \\
\hline \multicolumn{4}{|l|}{ Deprivation score } \\
\hline 1 (least deprived) & $6 / 24(25.0 \%)$ & & \\
\hline 2 & $51 / 164(31.1 \%)$ & $\mathrm{P}=0.09$ & \\
\hline 3 & 59 / $183(32.2 \%)$ & $1.32(0.95-1.82)$ & \\
\hline 4 (most deprived) & 9 / $14(64.3 \%)$ & & \\
\hline Behaviour & & & $\begin{array}{c}\text { Adjusted OR } \\
(95 \% \mathrm{CI})^{1}\end{array}$ \\
\hline Ever drink alcohol? & & $\mathrm{P}=0.28$ & $\mathrm{P}=0.24$ \\
\hline No & 123 / 374 (32.9\%) & 1 & 1 \\
\hline Yes & 2 / $11(18.2 \%)$ & $0.45(0.10-2.13)$ & $0.41(0.08-2.05)$ \\
\hline Ever kissed with tongues & & $P=0.006$ & $\mathrm{P}=0.82$ \\
\hline No & 83 / 290 (28.6\%) & 1 & 1 \\
\hline Yes & 42 / $95(44.2 \%)$ & $1.98(1.23-3.19)$ & $0.94(0.54-1.63)$ \\
\hline $\begin{array}{l}\text { Ever engaged in genital } \\
\text { touching }{ }^{2}\end{array}$ & & $\mathrm{P}=0.003$ & $\mathrm{P}=0.64$ \\
\hline No & 102 / 342 (29.8\%) & 1 & 1 \\
\hline Yes & $23 / 43(53.5 \%)$ & $2.71(1.42-5.14)$ & $1.19(0.59-2.40)$ \\
\hline Ever had oral sex ${ }^{3}$ & & $P=0.07$ & $\mathrm{P}=0.55$ \\
\hline No & 119 / 375 (31.7\%) & 1 & 1 \\
\hline Yes & $6 / 10(60.0 \%)$ & $3.23(0.89-11.65)$ & $1.51(0.39-5.87)$ \\
\hline Ever had vaginal sex & & $\mathrm{P}<0.001$ & $\mathrm{P}<0.001$ \\
\hline No & 41 / $222(18.5 \%)$ & 1 & 1 \\
\hline Yes & 84 / $163(51.5 \%)$ & $4.69(2.97-7.42)$ & $4.81(3.02-7.66)$ \\
\hline Menstrual hygiene ${ }^{4}$ & & $\mathrm{P}=0.002$ & $\mathrm{P}=0.004$ \\
\hline Pads only (+/- pants) & 68 / 202 (33.7\%) & 1 & 1 \\
\hline Cloths only $(+/-$ & $12 / 71(16.9 \%)$ & $0.40(0.20-0.80)$ & $0.45(0.22-0.94)$ \\
\hline
\end{tabular}




\begin{tabular}{|c|c|c|c|}
\hline pants) & & & \\
\hline Pants only & 15 / 29 (51.7\%) & $2.11(0.96-4.63)$ & $2.75(1.17-6.46)$ \\
\hline $\begin{array}{l}\text { Cloth \& pads }(+/- \\
\text { pants) }\end{array}$ & $30 / 79(38.0 \%)$ & $1.21(0.70-2.07)$ & $1.16(0.65-2.08)$ \\
\hline Ever cleanse inside vagina & & $\mathrm{P}=0.001$ & $\mathrm{P}=0.09$ \\
\hline No & 95 / 327 (29.1\%) & 1 & 1 \\
\hline Yes & 30 / 58 (51.7\%) & $2.62(1.48-4.62)$ & $1.70(0.92-3.16)$ \\
\hline \multicolumn{4}{|l|}{ Biological } \\
\hline HSV-2 & & $\mathrm{P}=0.45$ & $\mathrm{P}=0.48$ \\
\hline Negative & 121 / $376(32.2 \%)$ & 1 & 1 \\
\hline Positive & $4 / 9(44.4 \%)$ & $1.69(0.44-6.39)$ & $1.70(0.40-7.29)$ \\
\hline Chlamydia trachomatis & & $\mathrm{P}=0.15$ & $\mathrm{P}=0.76$ \\
\hline Negative & 120 / 376 (31.9\%) & 1 & 1 \\
\hline Positive & $5 / 9(55.6 \%)$ & $2.67(0.70-10.11)$ & $1.25(0.31-5.02)$ \\
\hline Neisseria gonorrhoeae & & $P=0.03$ & $\mathrm{P}=0.05$ \\
\hline Negative & 120 / 378 (31.7\%) & 1 & 1 \\
\hline Positive & 5 / 7 (71.4\%) & $5.37(1.03-28.10)$ & $5.70(0.91-35.56)$ \\
\hline Trichomonas vaginalis & & $\mathrm{P}=0.02$ & $\mathrm{P}=0.79$ \\
\hline Negative & 115 / 368 (31.3\%) & 1 & 1 \\
\hline Positive & 10 / 17 (58.8\%) & $3.14(1.17-8.46)$ & $1.16(0.39-3.45)$ \\
\hline \multicolumn{4}{|l|}{$\begin{array}{l}\text { Active syphilis } \\
(\mathrm{RPR}+/ \mathrm{TPPA}+)\end{array}$} \\
\hline Negative & 125 / 385 (32.9\%) & - & - \\
\hline Positive & $0(-)$ & - & - \\
\hline HIV & & $\mathrm{P}=0.24$ & $\mathrm{P}=0.06$ \\
\hline Negative & 123 / 382 (32.2\%) & 1 & 1 \\
\hline Positive & $2 / 3(66.7 \%)$ & $4.21(0.38-46.89)$ & $10.44(0.90-121.5)$ \\
\hline Mycoplasma genitalium & & $\mathrm{P}=0.005$ & $\mathrm{P}=0.02$ \\
\hline Negative & 118 / 376 (31.4\%) & 1 & 1 \\
\hline Positive & $7 / 9(77.8 \%)$ & 7.65 (1.57-37.39) & $6.01(1.08-33.56)$ \\
\hline Bacterial vaginosis $^{5}$ & & $P=0.002$ & $\mathrm{P}=0.05$ \\
\hline Normal & $71 / 261(27.2 \%)$ & 1 & 1 \\
\hline Intermediate & 9 / $28(32.1 \%)$ & $1.27(0.55-2.93)$ & $0.94(0.36-2.44)$ \\
\hline BV & 45 / 95 (47.4\%) & $2.41(1.48-3.92)$ & $1.93(1.13-3.29)$ \\
\hline
\end{tabular}

${ }^{1}$ Behavioural factors adjusted for age (a priori), deprivation score, and vaginal sex. Biological factors adjusted for age, deprivation score, vaginal sex, menstrual hygiene and vaginal cleansing. ${ }^{2}$ Sexual touching with a man/boy where girl touched his penis with her hand, he touched her vagina with his hand, or he rubbed his penis on her legs/buttocks/genitals but did not have vaginal sex. ${ }^{3}$ Ever had man/boy put his penis in girl's mouth, or he licked/sucked the girl's genitals. ${ }^{4}$ Sanitary products used for menstrual hygiene; most girls who reported using pads or cloths also reported wearing pants (underwear). Restricted to girls who have passed menarche $(\mathrm{N}=381)$. ${ }^{5}$ Missing data for 1 girl. 
Table 3. Association of bacterial species with any HPV infection among 385 adolescent girls attending secondary school in Mwanza, Tanzania

\begin{tabular}{|c|c|c|c|c|}
\hline & $\begin{array}{c}\text { N with HPV / total } \\
\text { N (\%) }\end{array}$ & $\begin{array}{l}\text { Crude OR } \\
(95 \% \text { CI) }\end{array}$ & $\begin{array}{c}\text { Adjusted OR } \\
(95 \% \mathrm{CI})^{1}\end{array}$ & $\begin{array}{c}\text { Adjusted OR } \\
(95 \% \mathrm{CI})^{2}\end{array}$ \\
\hline \multicolumn{5}{|c|}{ Presence/absence } \\
\hline A. vaginae ${ }^{3}$ & & $P<0.001$ & $\mathrm{P}<0.001$ & $\mathrm{P}=0.002$ \\
\hline Absent & 49 / $220(22.3 \%)$ & 1 & 1 & 1 \\
\hline Present & 63 / $139(45.3 \%)$ & $2.89(1.82-4.59)$ & $2.30(1.40-3.76)$ & $2.19(1.32-3.64)$ \\
\hline G. vaginalis 4 & & $\mathrm{P}<0.001$ & $\mathrm{P}=0.02$ & $\mathrm{P}=0.03$ \\
\hline Absent & $31 / 145(21.4 \%)$ & 1 & 1 & 1 \\
\hline Present & 87 / $209(41.6 \%)$ & $2.62(1.62-4.25)$ & $1.87(1.12-3.14)$ & $1.79(1.05-3.04)$ \\
\hline L. vaginalis 5 & & $\mathrm{P}<0.001$ & $\mathrm{P}=0.03$ & $\mathrm{P}=0.04$ \\
\hline Absent & 59 / $131(45.0 \%)$ & 1 & 1 & 1 \\
\hline Present & 64 / $242(26.4 \%)$ & $0.44(0.28-0.69)$ & $0.58(0.36-0.93)$ & $0.60(0.37-0.98)$ \\
\hline L. crispatus ${ }^{6}$ & & $\mathrm{P}<0.001$ & $\mathrm{P}=0.005$ & $\mathrm{P}=0.005$ \\
\hline Absent & 55 / $120(45.8 \%)$ & 1 & 1 & 1 \\
\hline Present & $60 / 238(25.2 \%)$ & $0.40(0.25-0.63)$ & $0.49(0.30-0.81)$ & $0.48(0.29-0.80)$ \\
\hline L. gasseri 7 & & $\mathrm{P}=0.91$ & $\mathrm{P}=0.86$ & $\mathrm{P}=0.76$ \\
\hline Absent & 98 / $300(32.7 \%)$ & 1 & 1 & 1 \\
\hline Present & 24 / 75 (32.0\%) & $0.97(0.56-1.67)$ & $1.06(0.59-1.89)$ & $1.10(0.61-1.99)$ \\
\hline L. iners 8 & & $P=0.08$ & $\mathrm{P}=0.20$ & $\mathrm{P}=0.37$ \\
\hline Absent & 16 / $68(23.5 \%)$ & 1 & 1 & 1 \\
\hline Present & $106 / 311(34.1 \%)$ & $1.68(0.92-3.08)$ & $1.51(0.79-2.89)$ & $1.35(0.69-2.63)$ \\
\hline L. jensenii ${ }^{5}$ & & $\mathrm{P}<0.001$ & $\mathrm{P}<0.001$ & $\mathrm{P}=0.001$ \\
\hline Absent & 83 / 198 (41.9\%) & 1 & 1 & 1 \\
\hline Present & 37 / 175 (21.1\%) & $0.37(0.23-0.59)$ & $0.44(0.27-0.71)$ & $0.44(0.27-0.73)$ \\
\hline \multicolumn{5}{|c|}{$>1,000,000 / \mathrm{mL}$} \\
\hline A. vaginae 3 & & $\mathrm{P}<0.001$ & $\mathrm{P}<0.001$ & $\mathrm{P}=0.001$ \\
\hline No & 55 / 239 (23.0\%) & 1 & 1 & 1 \\
\hline Yes & 57 / $120(47.5 \%)$ & $3.03(1.90-4.83)$ & $2.37(1.44-3.92)$ & $2.33(1.39-3.91)$ \\
\hline G. vaginalis 4 & & $\mathrm{P}<0.001$ & $\mathrm{P}=0.02$ & $\mathrm{P}=0.02$ \\
\hline No & 47 / 195 (24.1\%) & 1 & 1 & 1 \\
\hline Yes & $71 / 159(44.7 \%)$ & $2.54(1.61-4.00)$ & $1.83(1.12-2.98)$ & $1.83(1.10-3.03)$ \\
\hline L. vaginalis $\mathbf{5}$ & & $\mathrm{P}=0.57$ & $\mathrm{P}=0.75$ & $\mathrm{P}=0.68$ \\
\hline No & $91 / 269$ (33.8\%) & 1 & 1 & 1 \\
\hline Yes & 32 / 104 (30.8\%) & $0.87(0.53-1.41)$ & $0.92(0.54-1.55)$ & $0.89(0.52-1.53)$ \\
\hline L. crispatus 6 & & $\mathrm{P}<0.001$ & $\mathrm{P}=0.009$ & $\mathrm{P}=0.01$ \\
\hline No & 59 / $132(44.7 \%)$ & 1 & 1 & 1 \\
\hline Yes & 56 / $226(24.8 \%)$ & $0.41(0.26-0.64)$ & $0.52(0.32-0.85)$ & $0.52(0.32-0.87)$ \\
\hline L. gasseri 7 & & $\mathrm{P}=0.57$ & $\mathrm{P}=0.41$ & $\mathrm{P}=0.34$ \\
\hline No & $106 / 331(32.0 \%)$ & 1 & 1 & 1 \\
\hline Yes & 16 / $44(36.4 \%)$ & $1.21(0.63-2.34)$ & $1.35(0.67-2.73)$ & $1.42(0.69-2.91)$ \\
\hline L. iners 8 & & $\mathrm{P}=0.05$ & $\mathrm{P}=0.24$ & $\mathrm{P}=0.52$ \\
\hline No & 20 / 85 (23.5\%) & 1 & 1 & 1 \\
\hline Yes & 102 / $294(34.7 \%)$ & $1.73(0.99-3.01)$ & $1.43(0.79-2.59)$ & $1.22(0.66-2.25)$ \\
\hline L. jensenii ${ }^{5}$ & & $\mathrm{P}<0.001$ & $\mathrm{P}<0.001$ & $\mathrm{P}<0.001$ \\
\hline
\end{tabular}




\begin{tabular}{|lccccc|}
\hline No & $94 / 238(39.5 \%)$ & 1 & 1 & 1 \\
Yes & $26 / 135(19.3 \%)$ & $0.37(0.22-0.60)$ & 0.40 & $(0.24-0.68)$ & $0.38(0.22-0.65)$ \\
\hline
\end{tabular}

${ }^{1}$ Adjusted for age (a priori), deprivation score, and vaginal sex. ${ }^{2}$ Adjusted for age (a priori), deprivation score, vaginal sex, menstrual hygiene and vaginal cleansing. ${ }^{3}$ Missing data for 26 girls. ${ }^{4}$ Missing data for 31 girls. ${ }^{5}$ Missing data for 12 girls. ${ }^{6}$ Missing data for 27 girls. ${ }^{7}$ Missing data for 10 girls. ${ }^{8}$ Missing data for 6 girls. 
Figure 1. HPV genotype-specific prevalence ${ }^{1}$ among 385 girls attending secondary school in Mwanza, Tanzania
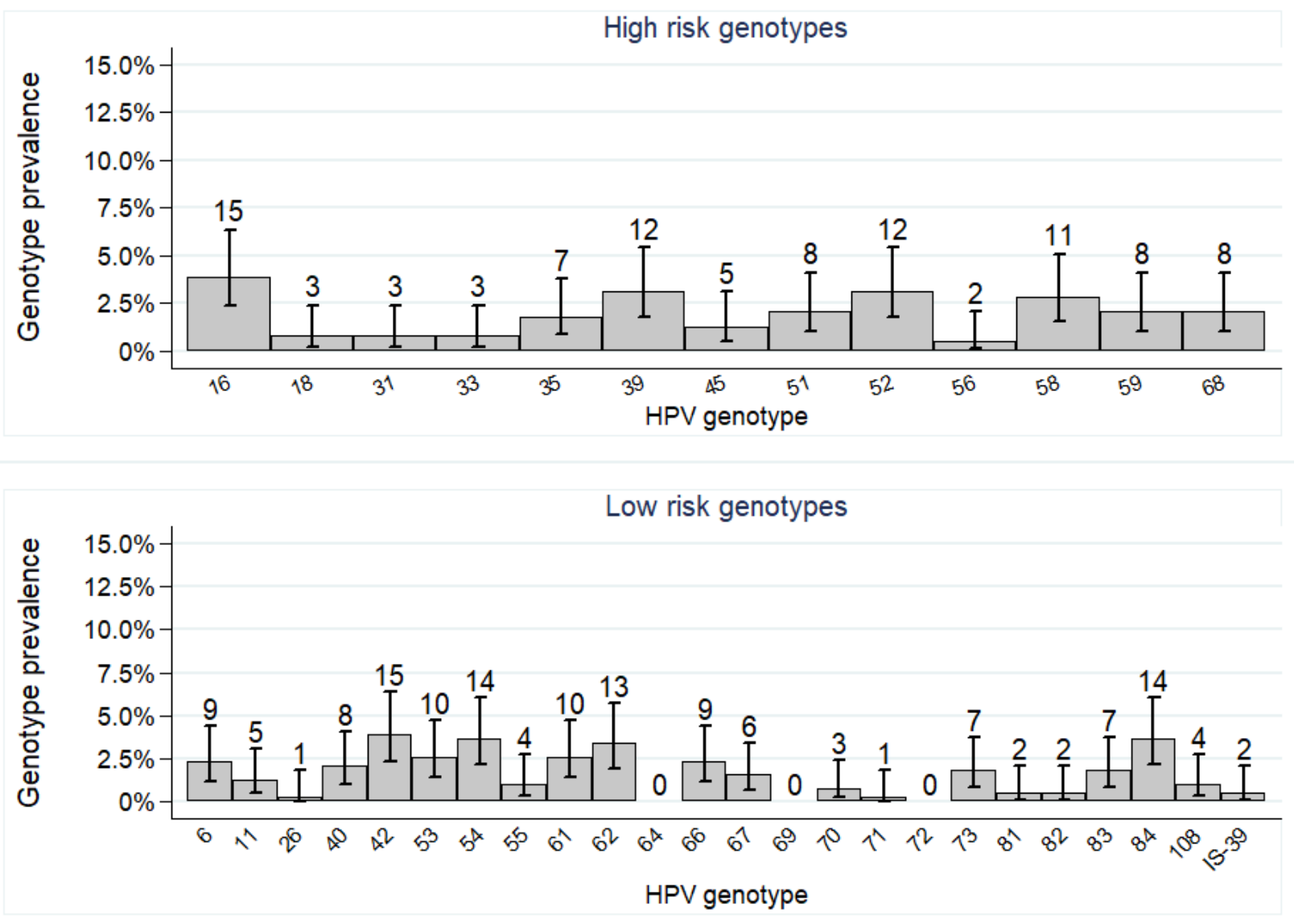

${ }^{1}$ Vertical lines indicate $95 \%$ confidence intervals and numbers are raw frequencies. 